\title{
O CASO VENEZUELANO COMO DESAFIO À INTEGRAÇÃO REGIONAL DEMOCRÁTICA SUL-AMERICANA
}

\author{
William Paiva Marques Júnior*
}

\section{RESUMO:}

A complexa e conturbada realidade contemporânea da Venezuela demonstra a existência de diversos fatores que desafiam a integração regional sul-americana. A viabilidade de projetos integracionistas regionais deposita suas esperanças na ampliação da democracia, do constitucionalismo e da cidadania. Utiliza-se, como metodologia, de pesquisa do tipo bibliográfica por meio da análise de livros, artigos jurídicos, documentos internacionais, da legislação e da jurisprudência. A pesquisa é pura e de natureza qualitativa, com finalidade descritiva e exploratória.

PALAVRAS CHAVES: Venezuela; Democracia; Integração; América do Sul; Contemporaneidade.

\section{VENEZUELAN CASE AS A CHALLENGE TO DEMOCRATIC REGIONAL INTEGRATION}

\begin{abstract}
:
Venezuela's complex and troubled contemporary reality demonstrates the existence of several factors that challenge South American regional integration. The feasibility of regional integrationist projects places its hopes in the expansion of democracy, constitutionalism and citizenship. It is used, as a methodology, bibliographic research through the analysis of books, legal articles, international documents, legislation and jurisprudence. The research is pure and qualitative, with descriptive and exploratory purpose.
\end{abstract}

KEY-WORDS: Venezuela; Democracy; Integration; South America; Contemporary.

\section{Introdução}

Questiona-se o futuro da integração regional sul-americana principalmente quanto a sua sobrevivência em uma relação de legitimação na qual os cidadãos e os governos aparentemente apresentam-se em posições antagônicas, afinal, a existência de conflitos é ínsita ao espírito democrático.

\footnotetext{
* Doutor e Mestre em Direito Constitucional pela UFC. Professor Adjunto I do Departamento de Direito Privado da Faculdade de Direito da UFC de Direito Civil II (Direito das Obrigações) e Direito Civil V (Direito das Coisas). Coordenador da Graduação em Direito da UFC (2014 a 2017). Assessor do Reitor da UFC. Foi Advogado Júnior da ECT (Empresa Brasileira de Correios e Telégrafos), de 2008 a 2011. E-mail: williamarques.jr@gmail.com
} 
A realidade contemporânea na América do Sul, especialmente na Venezuela demostra que a relação entre a democracia e a constituição revela-se como uma constante necessidade.

As relações internacionais na primeira década do Século XXI foram marcadas por acontecimentos de grande relevo, como a guerra ao terror, promovida principalmente pelos Estados Unidos, a ascensão econômica chinesa, não apenas no entorno asiático, mas também em escala mundial, a mudança nos termos de troca em favor dos países produtores de bens primários, a extraordinária dinâmica de crescimento dos anos de 2003 a 2007, a crise financeira sistêmica desde 2008 e a recuperação do crescimento econômico dos países em desenvolvimento. Esses fenômenos sinalizam modificações estruturais no sistema econômico e político internacional, configurando novas relações estatais e o fortalecimento de outros projetos integracionistas, dentre os quais avultam em importância o MERCOSUL e, mais recentemente o PROSUL, ambos na América do Sul.

Diversos temas servem de desafio à efetividade da democracia e do constitucionalismo na América do Sul, especialmente as deficiências na educação, o caos no acesso à saúde, a problemática ambiental, as violações estatais e não-estatais aos direitos humanos, a necessidade de combate ao narcotráfico e à violência endêmica, dentre outras questões fundamentais para o desenvolvimento da região.

Desde a morte de Hugo Chávez ocorrida em 2013, a Venezuela vive inegável processo de crise econômica, política e social. O vazio de poder se acentuou com a pouca efetividade de Nicolás Maduro e com a baixa do preço do petróleo no mercado internacional.

Com o agravamento da crise econômica, o governo de Nicolás Maduro aumentou a repressão exercida contra seus opositores, as detenções arbitrárias, violações sistemáticas aos direitos humanos, a falta de eleições livres e o cerceamento das liberdades individuais, inclusive com a questionável eleição de uma nova Assembleia Nacional Constituinte.

Em dezembro de 2016, a Venezuela foi suspensa do MERCOSUL, sob o argumento jurídico que o país deixou de cumprir com os compromissos assumidos na sua adesão ao Bloco e, portanto, perdeu todos os direitos de participação. Em 2019, o Grupo de Lima, requereu ao Tribunal Penal Internacional (TPI) que investigue Nicolás Maduro, considerando a grave situação humanitária na Venezuela, a violência do regime de Maduro contra a população civil e a rejeição de assistência internacional, que, segundo manifestação do Grupo de Lima, constituem "crime contra a humanidade". 
Utiliza-se, como metodologia, de pesquisa do tipo bibliográfica por meio da análise de livros, artigos jurídicos, documentos internacionais e da legislação. A pesquisa é pura e de natureza qualitativa, com finalidade descritiva e exploratória.

\section{Surgimento, desenvolvimento e características da integração regional sul-americana}

A formação histórica da integração regional da América do Sul remonta ao período de colonização dos portugueses e dos espanhóis, desde o Século XVI e implicou a formação de uma epistemologia informada pela imposição de valores europeus para a realidade do Sul, que implicaram uma dificuldade de superação dessa lógica de subalternidade mediante a formação de um modelo próprio, além da mera subsunção do modelo integracionista nos moldes europeus.

De acordo com Gianfranco Pasquino (1998, pág. 632), "Integração", lato sensu, significa a superação das divisões e rupturas e a união orgânica entre os membros de uma organização. De regra, esta organização é, atualmente, o Estado-nação; são, pois, dissensões entre os vários grupos que fazem parte do Estado. Se a organização é constituída de uma federação, as fraturas decorrem do grau de heterogeneidade dos Estados-membros. A Integração pode ser vista como um processo ou como uma condição. Se for vista como uma condição, falar-se-á de organizações mais ou menos integradas.

Por seu turno Sandra C. Negro (2010, p. 34), aduz que se pode dizer da existência de algumas diferenças importantes peculiares à integração. Uma das principais é que, nas organizações internacionais, o mecanismo de cooperação intergovernamental é privilegiado, enquanto no processo de integração tem precedência ou tendem a adquiri-la as instituições criadas na tomada de decisões e na aplicação do ordenamento jurídico próprio da integração, para alcançar, em última instância, como evidenciado pela experiência europeia, a supranacionalidade.

Conforme aduzem Amado Luiz Cervo e Clodoaldo Bueno (2010, págs. 486 e 487), as relações entre o Brasil e seus vizinhos responderam a apelos históricos contraditórios: isolamento, boa vizinhança, liderança. Imagens e percepções dos dois lados condicionaram a estratégia regional. Também as afinidades e diferenças. A Argentina, rival diminuída, disputou com o Brasil a influência sobre Uruguai, Paraguai e Bolívia. O Brasil contou historicamente com o Chile e, desde o Tratado de Cooperação Amazônica, de 1978, com os países amazônicos. A confiança mútua engendrada nas relações com a Argentina recuperou a ideia de Rio Branco de liderar a América do Sul em sintonia com esse vizinho maior, se 
possível. No início dos anos de 1990, o Brasil traçou uma estratégia regional que permaneceria invariável: reforço do MERCOSUL com a convergência política entre Brasil e Argentina e organização do espaço sul-americano com autonomia perante os Estados Unidos.

De acordo com Samuel Pinheiro Guimarães (2012, pág. 93), os destinos da América do Sul e da integração regional estão profundamente vinculados. A integração determinará o grau de resistência da região à crise e a suas repercussões nos países altamente desenvolvidos e na China.

Atualmente observa-se que a América do Sul (apesar de suas assimetrias), campeia como modelo predominantemente democrático no Hemisfério Sul, fator considerado fundamental para o êxito do processo integracionista.

Os valores informativos da democracia, do constitucionalismo, da cooperação, da harmonia, da complementaridade e da solidariedade, em substituição aos paradigmas da individualidade e da competitividade (norteadores das relações na realidade contemporânea), são fundamentais para o êxito do longo processo integracionista da América do Sul.

Os avanços na integração sul-americana vão muito além da dimensão econômica abarcando também o lado político, para a evolução dos países, individualmente e em conjunto. A América do Sul representa a região mais democrática no mundo em desenvolvimento. A existência de regimes democráticos com inclusão social no conjunto da América do Sul leva, por sua vez, a um esforço de traduzir em manifestações coletivas o compromisso com a democracia. Já existia, no MERCOSUL, o Protocolo de Ushuaia. Em 2011, adotou-se, também na UNASUL, uma cláusula democrática, idêntico exemplo seguido pelo PROSUL.

O recém-criado Fórum para o Progresso e Desenvolvimento da América do Sul (PROSUL) representa um processo de integração mais pragmático e orientado para resultados econômicos e para o fortalecimento da democracia na região. A partir da criação do PROSUL, o MERCOSUL assume um papel mais voltado para o livre comércio. Com a nova função do MERCOSUL em 2019 foram priorizadas relações do Bloco com a União Europeia, com a Associação Europeia de Livre Comércio e com o Canadá.

De acordo com Florisbal de Souza Del'Olmo e Eduardo Daniel Lazarte Moron (2019, online), no contexto latino-americano, observa-se que a tendência de formação de espaços de relações privilegiadas entre países, por meio de projetos de integração comercial, incluindo a formação de blocos econômicos regionais, não é recente e configura elemento 
central nos esforços despendidos pelos governos locais com vistas a promover uma melhor inserção dos Estados da região no mercado internacional.

Deve-se buscar um ritmo e modelo original na integração dos países sulamericanos, considerando-se que o modelo integrativo europeu, ocorrido após a Segunda Guerra Mundial, aconteceu numa velocidade acelerada, haja vista a necessidade de recuperação da economia europeia, naquele momento em fase de dependência dos aportes financeiros dos Estados Unidos (por meio do Plano Marshall). A influência exacerbada do aspecto econômico sobre a integração europeia pode ser substituída por outros parâmetros no modelo sul-americano, tais como o meio ambiente, as águas, a infra-estrutura, o efetivo compromisso na redução das assimetrias regionais e a energia.

A realidade contemporânea nos países da América do Sul demonstra a existência de diversos fatores que desafiam a integração regional sul-americana, tais como: altos níveis de corrupção estatal através das constantes revelações de relações espúrias entre altos executivos com interesses em decisões governamentais; assimetrias e carências na infraestrutura; as profundas desigualdades sociais e econômicas; o poder paralelo do narcotráfico e a estrutura do crime organizado em âmbito transnacional (muitas vezes institucionalizado); violência urbana em níveis alarmantes (segundo dados coletados pela ONU (2019, online), das dez cidades mais violentas do mundo todas se encontram na América Latina) e as constantes violações aos direitos humanos; as vicissitudes ambientais (poluição do ar e da água, desmatamento das florestas, utilização de técnicas agrícolas devastadoras à vida, dentre diversas outras); baixos níveis educacionais; acesso deficitário aos programas de saúde, dentre diversas outras questões que devem ser enfrentadas para a plenitude do processo integracionista.

O fortalecimento e a consolidação das ainda frágeis instituições nas democracias sul-americanas não devem passar por líderes personalistas carismáticos, caso contrário, estarse-iam reavivando o populismo e a autocracia. O caminho correto a ser seguido é outro: mediante a participação madura e ativa dos cidadãos, com instituições fortalecidas, legítimas, transparentes e eficazes; com a existência de um sistema de freios e contrapesos entre os poderes, com lideranças democráticas e uma sólida estrutura cidadão.

Na perspectiva da integração almejada pela América do Sul, faz-se necessário um modelo definido de consolidação de uma epistemologia local, valorização da cultura autóctone, na qual se respeite toda a diversidade cultural sul-americana, de um espaço de 
troca de valores menos dependente das vontades governamentais, com um patamar inclusivo de cidadania e participação política democrática. Dá-se início, dessa forma, à etapa atual da conscientização no imaginário popular da integração da América do Sul, perfazendo uma genuína integração, na busca da superação dos problemas comuns, incluindo a realidade caótica vivenciada na Venezuela contemporânea.

\section{A América do Sul como espaço de debate para a democracia e para o constitucionalismo e seus reflexos na integração regional}

Esclarece Hans Kelsen (2.005, pág. 403) que o princípio de uma separação de poderes, compreendido literalmente ou interpretado como um princípio de divisão de poderes, não é essencialmente democrático. Ao contrário, correspondente à ideia de democracia é a noção de que todo o poder deve estar concentrado no povo, e, onde não é possível a democracia direta, mas apenas a indireta, que todo o poder deve ser exercido por um órgão colegiado cujos membros sejam eleitos pelo povo e juridicamente responsáveis para com o povo. Caso esse órgão tenha apenas funções legislativas, os outros órgãos que têm de executar as normas emitidas pelo órgão legislativo devem ser responsáveis para com ele, mesmo que também tenham sido eleitos pelo povo.

O fortalecimento e a consolidação das ainda frágeis instituições nas democracias latino-americanas não devem passar por líderes personalistas carismáticos, caso contrário, estar-se-iam reavivando o populismo e a autocracia. O caminho correto a ser seguido é outro: mediante a participação madura e ativa dos cidadãos, com instituições fortalecidas, legítimas, transparentes e eficazes; com a existência de um sistema de freios e contrapesos entre os poderes, com lideranças democráticas e uma sólida estrutura cívica.

Sobre a necessidade de fortalecimento do valor democrático na América Latina para o futuro ante o passado problemático vaticina o historiador mexicano Enrique Krauze (2019, online):

El siglo XIX latinoamericano fue el del caudillismo militarista. El siglo XX sufrió el
redentorismo iluminado. Ambos siglos padecieron a los hombres 'necesarios'. Tal
vez en el siglo XXI despunte un amanecer distinto, plenamente democrático, donde
no haya hombres 'necesarios', donde los únicos necesarios seamos los ciudadanos
actuando libremente en el marco de las leyes y las instituciones.

As iniciativas de fortalecimento do protagonismo popular, por meio da incorporação de mecanismos de democracia direta e autogestão na América do Sul, são usurpadas pela predominância do Executivo como elemento recorrente na tradição política do 
País, caracterizada pelo hiperpresidencialismo e, em especial, nos casos equatoriano, boliviano e venezuelano pelo personalismo, nas figuras de Rafael Correa, Evo Morales e Hugo Chávez.

A herança econômica de décadas de inflação galopante com políticas legitimadas para combatê-la provocou um desmantelamento do Estado, produzindo um desarranjo na vida da camada mais pobre da população latino-americana. As reformas adotadas pelo Estado como estabilização monetária, interferência do Estado e certos mecanismos da política, economia e adoção de programas sociais norteados por critérios de eficiência, priorizaram os setores mais pobres da população. Por outro lado, o modelo estatizante de nacionalismo arraigado com o Estado assumindo o protagonismo no setor econômico, mobilizando apoio popular com política assistencialista, asfixiou o Estado que empreendeu um regime destinado à perpetuação no poder político.

Os problemas relacionados à América Latina estão concentrados na impossibilidade de garantia de bem-estar social compreendidos na sociedade de consumo, por sua vez, vulnerável às tentações do neopopulismo ideológico. O grande desafio é construir o arcabouço de um projeto que venha a garantir ampla expressão individual a ser outorgada pelo Estado primando pela autonomia cidadã não apenas na perspectiva existencial, mas também ideológica.

Na proposta de Bernardo Sorj e Danilo Martuccelli (2008, pág. 266), a política democrática se constrói sempre ao redor de um projeto de nação dentro do qual os indivíduos e os grupos sociais encontram valores comuns; de um Estado que propõe as regras do jogo com as quais os cidadãos se identificam e que permitem criar o sentimento de ser parte de um destino comum, e de uma comunidade nacional, produzindo sentimentos de dignidade e de auto-conhecimento. Diante desse imperativo iniludível da coesão social, o principal déficit do reformismo-tecnocrático foi não haver investido recursos suficientes na construção de sua legitimidade simbólica.

A democracia representativa informativa do Neoconstitucionalismo, na América do Sul, vive uma crise de legitimidade, na medida em que muitos cidadãos não se sentem representados pelo sistema político, tal cenário ficou bastante delineado nas manifestações populares de junho de 2013 ocorridas no Brasil.

No diagnóstico de Rubens Ricupero (2017, pág. 678), o movimento brasileiro de 2013 foi uma expressão a mais da grave crise mundial da democracia representativa, talvez 
até algo de mais grave, um profundo mal-estar com a baixa qualidade de vida produzida pelo desenvolvimento selvagem do país. Em todos os níveis- federal, estadual e municipal-, o governo mostrou que não havia entendido o sentido real dos protestos e, pelo seu comportamento imediatista, confirmou as piores expectativas das manifestações. Acuados por fenômeno que não compreendiam, os governos tiveram apenas um objetivo de curto prazo: esvaziar de novo as ruas e as praças, comprar de qualquer modo a volta à normalidade.

Ao tratar do interesse dos pobres com a democracia e com os direitos políticos aduz Amartya Sen (2010, pág. 200): "No momento em que de certa forma houve um teste da proposição de que os pobres em geral não se importam com direitos civis e políticos, as evidências foram inteiramente contrárias a essa afirmação".

Criado em um contexto de caos político, social, econômico e humanitário na Venezuela, o PROSUL não expressa de forma direta estratégias claras para os problemas dos refugiados venezuelanos, fato é que o país não se encontra presente no novo projeto integracionista. No plano prospectivo, observa-se que o PROSUL surge com o nítido objetivo de substituir a UNASUL. Nesse diapasão, o surgimento do PROSUL também é uma forma de países da região isolarem a Venezuela, governada por Nicolás Maduro. O aludido isolamento se dá porque Brasil, Argentina e Colômbia estão entre os países que não reconhecem a legitimidade de Maduro e consideram o líder oposicionista Juan Guaidó como presidente interino da Venezuela, desse modo, a disputa pela legitimidade presidencial na Venezuela reverbera no plano da interação regional sul-americana.

\section{A complexa realidade contemporânea na Venezuela como desafio imposto à democracia e à integração regional na América do Sul}

No início do Século XXI, as populações em quase toda a América do Sul, decepcionadas com as reformas estruturais neoliberais e com o desempenho social da democracia, depositaram suas esperanças elegendo novos líderes e conduzindo ao poder forças políticas aparentemente mais preocupadas com a defesa dos interesses nacionais e com questões referentes à pobreza e à desigualdade, segundo o escrutínio dos próprios eleitores.

Neste contexto, a lista dos novos presidentes foi grande: Hugo Chávez (Venezuela, 1998); Ricardo Lagos (Chile, 1999); Lula (Brasil, 2002); Néstor Kirchner (Argentina, 2003); Tabaré Vázquez (Uruguai, 2004); Evo Morales (Bolívia, 2005); Michelle Bachelet (Chile, 2006); e Alan Garcia (Peru, 2006). 
No diagnóstico de Edwin Williamson (2009, p. 612), a ascensão de Hugo Chávez teria repercussão para além das fronteiras da Venezuela. O seu empenho na solidariedade "bolivariana" entre as repúblicas latino-americanas, suportado pela riqueza do petróleo, poderia ter consequências sérias para a geopolítica da região.

Conforme noticia Alejandro Mendible (2013, p. 275), Hugo Chávez morreu em Caracas na terça - feira, dia 5 de março de 2013, e uma nova realidade política está emergindo na Venezuela, contando com um novo quadro, o MERCOSUL.

Desde a morte de Hugo Chávez, a Venezuela vive inegável processo de crise econômica, política e social. O vazio de poder se acentuou com a pouca efetividade de Nicolás Maduro e com a baixa do preço do petróleo no mercado internacional, uma vez que o País está bastante suscetível às baixas do preço do petróleo no mercado internacional por não ter conseguido se industrializar e criar uma infraestrutura.

A situação política do governo Nicolás Maduro na Venezuela indica intensa instabilidade social, política e econômica, com prejuízos para a democracia. O País passa por um profundo processo de crise econômica com filas que se formam ao redor dos supermercados ainda na madrugada, a falta de produtos básicos (alimentícios e de higiene pessoal), bem como a escassez de remédios nas prateleiras são problemas comuns. O país ostenta os maiores índices inflacionários e o maior défice fiscal do mundo. A queda no valor do petróleo no mercado internacional por volta de 50\% entre 2014 e 2015 impactou ainda mais o enfraquecimento da economia, uma vez que essa commodity corresponde à quase totalidade das receitas das exportações do País. Desse modo, o custo de vida aumenta rapidamente para a população, a incapacidade de importar enseja escassez, a dívida do País cresce rapidamente e a arrecadação do Governo é insuficiente para sustentar a continuidade de seus programas sociais, tornando a violência em níveis endêmicos no país.

Com o nefasto governo Nicolás Maduro, a realidade venezuelana quedou-se caótica: o dinheiro é papel sem valor; o país vive às escuras com os constantes "apagões elétricos"; as ruas são aterrorizadas por milícias governamentais dispostas a saquear, incendiar, estuprar e matar os oponentes.

O Presidente reagiu com radicalização por meio das prisões arbitrárias de diversos opositores políticos. Em 2015, foi aprovada a Resolução $\mathrm{n}^{\circ} .: 8.610$, que autoriza o uso da força para a contenção de manifestações. As supostas arbitrariedades e abusos cometidos pelo 
Governo venezuelano merecem um tratamento cuidadoso e atento da União das Nações SulAmericanas (UNASUL) para que os países da região não protagonizem o défice democrático.

Desta forma, observa-se que os países da América do Sul devem buscar a articulação e a coordenação de múltiplas culturas, bem como o respeito às diferenças, em vez da igualdade em homogeneização na perspectiva formal propugnada pela democracia consagrada no constitucionalismo clássico e mantida pelo neoconstitucionalismo europeucontinental.

A análise da situação atual da América do Sul revela que os movimentos de oposição não tendem para soluções militares (totalmente anacrônicas com os avanços da democracia na região), mas para a dominação política de líderes neopopulistas que se apresentam como alheios ao poder tradicional e prometem perspectivas inovadoras, tal qual ocorreu na Era de Hugo Chávez na Venezuela, iniciada com sua posse em 1998 até a sua morte em 2013.

Conforme propugnado por Norberto Bobbio (2015, pág. 29), como ideal do governo visível, a democracia sempre foi contraposta a qualquer forma de autoritarismo, a todas as formas de governo em que o sumo poder é exercitado de modo a ser subtraído na maior medida possível dos olhos dos súditos.

A ascensão de Nicolás Maduro ao poder em 2013, a queda contínua e expressiva do valor pago ao barril do petróleo (principal produto da economia local), desencadeou uma grave e profunda crise econômica na Venezuela, as instabilidades são transpostas igualmente para os aspectos políticos. A intensidade da crise provocou a escassez de produtos e serviços básicos no país, como alimentos, água, medicamentos, utensílios de higiene pessoal e energia elétrica.

$\mathrm{Na}$ América do Sul existe o compromisso de integração regional com a democracia firmado desde a década de 1990 pelos países que compõem o MERCOSUL.

Os Chefes dos Estados do Bloco do MERCOSUL firmaram, em 1997, a Declaração de Defesa da Democracia, com o escopo de preservação e fortalecimento da democracia representativa, valor compartilhado por todos os subscritores, constituindo-se em compromisso para os Estados signatários. O documento referenciado estabeleceu que a democracia representativa é o fundamento da legitimidade dos sistemas políticos e condição indispensável para a paz, a estabilidade e o desenvolvimento da região, assim como para o processo de integração hemisférica, no qual se encontram comprometidos os países 
integrantes do Bloco. Reafirmaram que toda agressão à democracia de um país da região constitui um atentado contra os princípios que fundamentam a solidariedade dos Estados americanos erigindo verdadeira cláusula democrática.

Em outubro de 2016, o Poder Judiciário Venezuelano, por meio do Tribunal Supremo, controlado pelas forças governamentais, interviu no Parlamento de maioria opositora, assim como declarou nulas todas as suas medidas. Na subsequente escalada de obstruções mútuas, o mesmo tribunal emitiu em fins de março de 2017 uma decisão na qual despojava a Assembleia Nacional de suas faculdades legislativas para transmiti-las ao presidente Nicolás Maduro. Essa medida, foi denunciada pela oposição como sendo um golpe de Estado e deu lugar a quatro meses de intensos protestos populares, sendo desafiada pela então Procuradora Geral, Luisa Ortega Díaz, que qualificou as manobras governamentais como interrupção da ordem constitucional estabelecida pela Constituição Venezuelana de 1999, delineada sob a influência de Hugo Chávez, padrinho político de Nicolás Maduro.

Desde abril de 2017, a Venezuela vive o acirramento de manifestações populares a favor e contra o governo, muitas delas violentas e que já deixaram centenas de mortos, milhares de feridos e muitos opositores encarcerados. $\mathrm{O}$ governo do presidente Nicolás Maduro deu posse a uma nova Assembleia Nacional Constituinte, iniciativa criticada pelo MERCOSUL porque é composta quase exclusivamente por representantes simpatizantes do governo de Nicolás Maduro, eleitos sob fortes suspeitas de fraudes. Neste sentido, vale ressaltar que todos os membros da Assembleia Nacional Constituinte ratificaram Maduro como presidente da Venezuela por unanimidade. Por exercer oposição às manobras de Maduro de se perpetuar no poder, a Procuradora Geral (Chefe do Ministério Público) da Venezuela, Luisa Ortega Díaz, foi destituída de suas funções pela Assembleia Nacional Constituinte em agosto de 2017. Os líderes dos Ministérios Públicos dos países que fazem parte do MERCOSUL repudiaram a destituição da procuradora-geral da Venezuela. Após alegar sofrer perseguições pessoais, a ex- Procuradora Geral requereu asilo político na Colômbia.

A partir de todos esses acontecimentos, Argentina, Brasil, Paraguai e Uruguai consideraram, invocando o Protocolo de Ushuaia sobre o compromisso democrático, que houve ruptura da ordem democrática na Venezuela ante o fundamento que de a Assembleia Nacional Constituinte teria usurpado as atribuições do Parlamento controlado pela oposição. 
Por seu turno deve-se ressalvar que o Art. $4^{\circ}$ - do Protocolo de Ushuaia prevê que: "No caso de ruptura da ordem democrática em um Estado Parte do presente Protocolo, os demais Estados Partes promoverão as consultas pertinentes entre si e com o Estado afetado". A ideia de consenso entre os Estados- partes é sempre a priorizada nos dispositivos componentes do Protocolo de Ushuaia.

A Venezuela passou a ser membro pleno do MERCOSUL em 2012 em meio a diversas negociações polêmicas. Para alguns, a decisão de incorporação da Venezuela, como foi feita, não atende às obrigações relacionadas à observância dos tratados previstas na Convenção de Viena. Carece de boa-fé, seja na acepção subjetiva de uma disposição do espírito de eticidade, lealdade e honestidade, seja na acepção objetiva de condutas norteadas para esta disposição no plano das relações internacionais.

Tendo por supedâneo razões de diversas ordens (técnicas, políticas e econômicas), os países fundadores do bloco econômico sul-americano (Argentina, Brasil, Paraguai e Uruguai), decidiram pela suspensão da Venezuela do MERCOSUL no final de 2016.

Em agosto de 2017, nova suspensão foi imposta pelo MERCOSUL à Venezuela. Nessa oportunidade, as razões determinantes foram jurídicas por conta da violação da cláusula democrática consagrada pelo Protocolo de Ushuaia.

Com a suspensão, os países do MERCOSUL objetivam convencer o governo venezuelano a estabelecer negociações com a oposição para saída da crise política que envolve o país, agravada com a convocação de uma assembleia constituinte.

Em Direito Internacional, a suspensão é uma das modalidades punitivas mais severas aplicáveis aos países que aderem aos Blocos. A suspensão ocorrida no final de 2016 se deu sob justificativa técnica, ao passo que a de agosto de 2017 , tem viés político ante o acirramento da crise interna pela convocação de uma assembleia constituinte situacionista pelo Presidente Nicolás Maduro.

Com as suspensões impostas à Venezuela pelo MERCOSUL, o direcionamento diplomático revela-se uma tentativa de demonstrar respaldo àqueles que tem lutado por forças democráticas dentro da Venezuela, especialmente a oposição.

O agravamento das crises social, política e econômica na Venezuela também reverberam no incremento do fluxo de venezuelanos para os países fronteiriços, especialmente Brasil e Colômbia. 
Em dezembro de 2017, o Brasil declarou "persona non grata" o então Encarregado de Negócios da Venezuela no Brasil, Geraldo Antonio Delgado Maldonado, como retaliação ao fato de o Embaixador do Brasil em Caracas, Ruy Carlos Pereira, haver sido declarado "persona non grata" pelo Governo venezuelano. No plano prático, a medida corresponde a uma expulsão de agente diplomático. O Ministério das Relações Exteriores Brasileiro agiu pautado pelo princípio da reciprocidade, reitor do Direito Internacional.

O artigo 9 da Convenção de Viena sobre Relações Diplomáticas de 1961, trata dos efeitos da declaração de um agente diplomático como "persona non grata". O objeto do instituto é permitir que um Estado retire um agente que não esteja contribuindo para o bom desenvolvimento do relacionamento diplomático ou que crie o potencial de que as relações diplomáticas não se desenvolvam num quadro de diálogo. Entretanto, no plano prático das relações internacionais, o instituto é mais empregado como instrumento de retaliação política, e a Venezuela tem frequentemente se utilizado desse mecanismo. A definição das competências para a prática desses atos no âmbito das relações internacionais é de política interna.

O governo de Nicolás Maduro não tem dado nenhum tipo de sinalização de que realmente deseja estabelecer um diálogo com a oposição. Esse isolamento tanto em âmbito político, quanto em âmbito relacional dificulta uma saída conciliatória dentro da própria Venezuela, piora a situação econômica, bem como impõe ainda mais sacrifícios à população.

Para um futuro emancipatório e inclusivo para a Venezuela propõe-se mais diálogo, uma democracia aberta à participação cidadã e um governo atento, acessível e sensível aos clamores sociais.

Para Daniela Mesquita de Leutchuk de Cademartori (2006, pág. 97), justamente por recusarem-se a reconhecer as existências autônomas da sociedade civil e política, os regimes totalitários impedem a formação de agentes econômicos e culturais independentes, capazes de promover as inovações necessárias, transformando-se em um obstáculo ao desenvolvimento autossustentado.

A evolução histórica dos países da América do Sul enquadra-se nesta colocação, na medida em que seus regimes autocráticos se mostram totalmente antitéticos às noções indissociáveis de desenvolvimento socioeconômico e democracia inclusiva.

Com a criação do PROSUL, em abril de 2018, os governos de Brasil, Argentina, Chile, Colômbia, Paraguai e Peru decidiram de forma conjunta suspender a sua participação 
da UNASUL em função da prolongada crise no organismo, considerando ainda a criação no mês anterior do PROSUL.

Em abril de 2019, o governo brasileiro denunciou o Tratado Constitutivo da União de Nações Sul-Americanas (UNASUL), formalizando sua saída da organização. A decisão foi comunicada oficialmente ao governo do Equador, país depositário do acordo, e surtirá efeitos transcorridos seis meses a contar de então.

Ainda em abril de 2019, o líder oposicionista Juan Guaidó, presidente autoproclamado, liderou uma fracassada tentativa de derrubada de Maduro. A tensão política resultou no ostensivo apoio das forças armadas ao governo Nicolás Maduro e na libertação do líder oposicionista Leopoldo López que foi libertado da sua prisão domiciliar por militares dissidentes.

Em janeiro de 2019, a resolução da oposição em retirar Maduro do poder e realizar novas eleições permanece intacta, esse fato motivou Juan Guaidó a autodeclarar-se presidente. Entretanto, os militares em sua maioria continuaram a apoiar Maduro, dificultando o papel projetado pela oposição.

O governo russo apoia o governo Maduro, sendo uma importante fonte de apoio financeiro ao país, fornecendo bilhões de dólares em empréstimos, garantidos por operações futuras de entrega de petróleo, isso aumenta a preocupação com a rápida escalada do conflito e da constante troca de provocações entre os governos russo e estadunidense.

Ao longo dos mais de 20 anos de chavismo, o poder público aumentou consideravelmente sua participação na economia, ampliando as oportunidades para burocratas públicos corruptos. Muitas das estatais venezuelanas foram criadas dos governos de Chávez e Maduro.

A Venezuela, muito rica em recursos naturais é detentora das maiores reservas petrolíferas do mundo. Diversas administrações sufocaram o desenvolvimento agrícola e industrial para privilegiar a exploração petrolífera, que responde pela quase totalidade das exportações do país.

Com o agravamento da crise econômica, política, social e humanitária, a Venezuela se transformou no país de onde saiu a maior quantidade de exilados do planeta, ultrapassando países em guerra, tais como: Afeganistão, Síria e Iraque. Todos os anos milhares de venezuelanos solicitam asilo, especialmente nos demais países da América do Sul. Com isso, Peru e Brasil entraram na lista global dos que mais acolhem o fluxo de 
solicitação de países dos que deixaram sua terra de origem. Conforme dados divulgados pela ONU/ACNUR (2019, online), cerca de 4 milhões de venezuelanos já saíram de seu país desde 2015, tornando essa uma das mais recentes e maiores crises de deslocamento forçado do planeta.

O governo de Maduro não tem dado nenhum tipo de sinalização de que realmente deseja estabelecer um diálogo com a oposição. Esse isolamento tanto em âmbito político, quanto em âmbito relacional dificulta uma saída conciliatória dentro da própria Venezuela, piora a situação econômica, bem como impõe ainda mais sacrifícios ao povo.

Na obra de ficção inspirada em fatos reais: "Noite em Caracas", a autora Karina Sainz Borgo (2019, pág. 195) ajuda a elucidar as vicissitudes de quem nem consegue sobreviver, tampouco fugir da decadência e da violência reinante em todos os níveis na Venezuela, revelando o período obscuro que o país atravessa:

Agora tudo transborda: a sujeira, o medo, a pólvora, a fome. Durante a sua agonia, o país enlouqueceu. Para viver, tivemos que fazer coisas que jamais imaginamos que seríamos capazes de fazer: roubar ou calar, voar no pescoço de alguém ou fingir olhar para o outro lado.

Para um futuro emancipatório e inclusivo para a Venezuela propõe-se mais diálogo, uma democracia aberta à participação cidadã e um governo atento, acessível e sensível aos clamores sociais.

A evolução histórica dos países da América do Sul enquadra-se nesta colocação, na medida em que seus regimes ditatoriais apresentaram-se totalmente antitéticos às noções indissociáveis de desenvolvimento socioeconômico e democracia inclusiva.

Assiste razão o ensinamento de Konrad Hesse (1991, pág. 32) ao dispor que não se deve esperar que as tensões entre ordenação constitucional e realidade política e social venham a deflagrar sério conflito. Não se poderia, todavia, prever o desfecho de tal embate, uma vez que os pressupostos asseguradores da força normativa da Constituição não foram plenamente satisfeitos.

Não se pode olvidar, contudo, que vários dos movimentos sociais libertários ocorridos ao longo da evolução da história venezuelana, revelaram-se em verdadeiros movimentos constituintes reivindicadores de pleno gozo dos direitos humanos fundamentais. Neste jaez, tem-se a legitimidade dos movimentos sociais libertários no país, na medida em que refletem os anseios políticos, institucionais, jurídicos e econômicos daquelas sociedades, tradicionalmente excluídas do acesso à mais rudimentar democracia cidadã e dos direitos humanos. 
O longo processo de integração sul-americana revela-se um caminho irreversível na busca de novos paradigmas democráticos e inclusivos, comprometidos com a implementação dos direitos humanos na formação do Estado Democrático de Direito, reavivado após as intensas manifestações populares ocorridas no Brasil em 2013 e 2015, bem como na Venezuela, ocorridos a partir de 2014.

Desde os anos de 1990, existe, na América do Sul, um crescente e significativo dinamismo no ajuste de acordos regionais, sub-regionais, multilaterais e bilaterais.

Como um dos problemas contemporâneos mais contundentes na América Latina apresenta-se o caso da Venezuela. Ao longo da última meia década, o Presidente Nicolás Maduro perseguiu e prendeu arbitrariamente opositores, anulou o Parlamento que apresentava-se como contraponto político, fechou os meios de comunicação não alinhados ao seu governo e militarizou o país, inclusive com milícias de apoiadores armados que atuam na intimidação de cidadãos contrários ao regime liberticida.

Todo esse caos gerou uma diáspora de milhões de venezuelanos. Em maio de 2018, o Presidente foi reeleito em sufrágio realizado sob o domínio do líder plenipotenciário, revelando um caso extremo de hiperpresidencialismo e perpetuação no poder com um alto custo para a democracia na região.

Sobre o caos atualmente reinante no país, relata Karina Sainz Borgo (2019, pág. 192): “Com dinheiro, tudo era simples e rápido. Possuí-lo tornava seu dono um alvo para os que o desejavam, mas muito pior era não tê-lo. E era assim que vivia a maioria. Em uma perpétua bancarrota."

Entre 2018 e 2019 a legitimidade de Maduro na Presidência venezuelana vem sendo cada vez mais questionada pela comunidade internacional. Um amplo e crescente grupo de países, liderado pelos Estados Unidos e incluindo o Brasil, exige a saída de Maduro do poder e sua substituição imediata pelo autoproclamado presidente interino, Juan Guaidó (líder oposicionista, presidente da Assembleia Nacional). Maduro tem a seu lado o apoio da China e da Rússia.

Ademais, de acordo com Juan Carlos Ruiz-Vásquez (2019, p. 443), a Venezuela pode ser descrita como narco-estado, não apenas por causa da influência que tem o tráfico de drogas na vida econômica do país, mas essencialmente porque as instituições públicas e seus funcionários estão diretamente envolvidos nas redes de tráfego. Altos funcionários do 
Executivo, do Exército e da Guarda Nacional participam ativamente dos negócios ilícitos e não apenas recebem subornos para deixar fazer ou passar nos esconderijos de drogas.

São tantas as crises provocadas na recente história da democracia latinoamericana que o discurso proferido pelo escritor colombiano Gabriel García Márquez (2019, online) ao receber o Prêmio Nobel de Literatura, em 1982 ainda faz sentido: “...a independência do domínio espanhol não nos colocou a salvo da demência." dos governantes de plantão.

A iniciativa do PROSUL se deu pela atuação dos atuais presentes do Chile (Sebastián Piñera) e da Colômbia (Iván Duque) garantindo papel protagonista a ambos países na construção do PROSUL.

Bolívia, Suriname e Uruguai, somados à Venezuela e à Guiana, são os únicos membros ativos restantes na UNASUL, após a saída de todos os demais países, com a criação do PROSUL, incluindo o Equador, país sede daquele Bloco.

Como diferenças visíveis, o PROSUL não deve ter um tratado e não será um organismo, como a UNASUL. Outra diferença objetiva se dá quanto aos países membros: enquanto participaram da UNASUL os 12 países sul-americanos, no PROSUL 4 deles ficaram de fora até o momento: Uruguai, Bolívia, Suriname e Venezuela. No aspecto subjetivo-ideológico, outra diferença é verificada pela seguinte constatação: enquanto as lideranças que fundaram a UNASUL tinham um perfil mais voltado à esquerda (o que não indica necessariamente que o bloco seja uma organização de esquerda), as do PROSUL são mais voltadas à direita (da mesma forma, não necessariamente o organismo é um fórum de direita) até porque, conforme vaticina Norberto Bobbio (2011, pág. 123), a distinção entre esquerda e direita refere-se ao diverso juízo positivo ou negativo sobre o ideal de igualdade, que deriva em última instância da diferença de percepção e de avaliação daquilo que torna os homens iguais ou desiguais, coloca-se em nível tão elevado de abstração que serve no máximo para distinguir dois tipos ideais.

No diagnóstico de Rubens Ricupero (2017, págs. 738 e 739), a diplomacia em geral fez sua parte e até então não se saiu mal em comparação a alguns outros setores. Chegou-se, porém, ao ponto extremo em que não mais é possível que um setor possa continuar a construir, se outros elementos mais poderosos, como o sistema político, comprazem-se em demolir. A partir de agora, mais ainda que no passado, a construção do 
Brasil terá que ser integral, e a contribuição da diplomacia na edificação dependerá da regeneração do todo.

A democracia pluralista não se coaduna com a ideologia da unanimidade. Seu maior desiderato é a promoção de uma institucionalização da divergência, ou seja, a permissão que representantes dos diferentes interesses gozem de liberdade para defender institucionalmente seus interesses, desde que estes se relacionem com os meios legais e participativos. Essa é a recomendação ideal para o êxito do projeto integracionista da América do Sul.

Para Gregorio Robles (1997, p. 153), se o pluralismo originalmente exigia a convivência no âmbito da democracia formal, hoje exige o desenvolvimento de uma democracia material (substantiva), estabelecida portanto não só em liberdades 'vazias' , mas também em critérios de política positiva que, do ponto de vista ético, não pode encontrar um assento na idéia individualista, mas na ideia da solidariedade e da responsabilidade.

Observa-se também que o "imperativo democrático" progressivamente toma lugar entre as prioridades da ONU, interpretado como um princípio de legitimidade democrática entre os direitos da coletividade e os direitos individuais civis e políticos. Por isso, vários comunicados foram expedidos pelo alto comissário de Direitos Humanos da Organização das Nações Unidas pedindo à Venezuela que abdique da violência e do assédio contra integrantes da oposição ao governo Nicolás Maduro.

Decerto o constructo democrático e garantista nos países acometidos pelos movimentos sociais libertários, na América do Sul, amoldam-se à constatação de Amartya Sen (2.011, pág. 236) consoante a qual: a liberdade democrática pode certamente ser usada para promover a justiça social e favorecer uma política melhor e mais justa. O processo, entretanto, não é automático e exige um ativismo por parte dos cidadãos politicamente engajados.

Portanto, inequívoco que a defesa inquebrantável da democracia é fundamental para o êxito do processo integracionista regional sul-americano devendo haver o enfrentamento dos problemas da Venezuela pelo MERCOSUL, a UNASUL e, mais recentemente, pelo PROSUL.

\section{Considerações Finais}

A atual conjuntura dos países da América do Sul demonstra que as mudanças estruturais jurídicas, sociais, políticas e institucionais são contagiosas, trata-se de um caminho 
irreversível na busca de novos paradigmas democráticos e inclusivos, comprometidos com a implementação do constitucionalismo inclusivo e da democracia na construção do Estado de Direito.

Constitucionalismo e democracia representam conceitos distintos. Um pode existir sem o outro. A realidade contemporânea demostra que a relação entre a democracia e a Constituição se revela como constante necessidade. O escopo fundamental da constituição moderna é a introdução de mecanismos reativos às mudanças não permitidas. No contexto do modelo imanente ao neoconstitucionalismo europeu-continental, o valor democrático é materializado por meio da democracia representativa e majoritária.

O resgate da democracia representará a redenção dos povos sul-americanos, cada vez mais envolvidos em discussões atreladas à legitimidade popular, promovidos pelo clamor do povo em resposta aos anseios de uma elite que busca de forma desenfreada a maximização e perpetuação de seus benefícios econômicos e políticos.

O governo de Nicolás Maduro não tem dado nenhum tipo de sinalização de que realmente deseja estabelecer um diálogo com a oposição. Esse isolamento tanto em âmbito político, quanto em âmbito relacional dificulta uma saída conciliatória na Venezuela, piora a situação econômica, bem como impõe ainda mais sacrifícios à população, gerando um sério problema humanitário relativo aos refugiados e reverbera na efetividade dos projetos integracionistas sul-americanos.

A crise só se aprofundou fazendo com que, todos os anos milhares de venezuelanos solicitem asilo, especialmente nos demais países da América do Sul, implicando, segundo a ONU que o número de refugiados ultrapasse o de países em guerra, tais como: Afeganistão, Síria e Iraque.

Para um futuro emancipatório e inclusivo para a Venezuela propõe-se mais diálogo, uma democracia aberta à participação cidadã e um governo atento, acessível e sensível às diferenças e aos clamores sociais.

A existência de conflitos é da natureza democrática. Nessa ordem de ideias, um elemento central para o êxito da integração regional sul-americana é a busca na solução para a grave crise atualmente vivenciada pela Venezuela. Portanto, faz-se essencial o diálogo diplomático, político e democrático para viabilizar a unidade da América do Sul.

A única saída viável na construção de um genuíno projeto integracionista regional sul-americano se dá pela valorização da política democrática que reúne condições de articular 
a complexidade e fundar as bases necessárias para o resgate da confiança dos cidadãos venezuelanos, na defesa de sua dignidade e de seus direitos .

\section{Referências bibliográficas}

BOBBIO, Norberto. Democracia e segredo. Tradução: Marco Aurélio Nogueira. São Paulo: Editora Unesp, 2015.

BOBBIO, Norberto. Direita e esquerda: razões e significados de uma distinção política. Tradução: Marco Aurélio Nogueira. 3ª- edição. São Paulo: Editora UNESP, 2011.

BORGO, Karina Sainz. Noite em Caracas. Tradução de Livia Deorsola. Rio de Janeiro: Intrínseca, 2019.

CADEMARTORI, Daniela Mesquita Leutchuk de. O diálogo democrático: Alain Touraine, Norberto Bobbio e Robert Dahl. Curitiba: Juruá, 2.006.

CERVO, Amado Luiz, BUENO, Clodoaldo. História da política exterior do Brasil. $3^{\text {a }}$ edição. 2 $2^{\mathrm{a}}$ - reimpressão. Brasília: Editora Universidade de Brasília, 2010.

DEL'OLMO, Florisbal de Souza. MORON, Eduardo Daniel Lazarte. Blocos Econômicos ou Áreas de Livre Comércio na América do Sul: Reflexões sobre a Aliança do Pacífico e o MERCOSUL. Disponível em: $<$ http://www.publicadireito.com.br/artigos/?cod=624c54021cda44b5 $>$. Acesso em: 15 de agosto de 2019.

GUIMARÃES, Samuel Pinheiro. A perspectiva brasileira da integração sul-americana. In: PATRIOTA, Antônio de Aguiar (organizador). A América do Sul e a integração regional. Brasília: FUNAG, 2012.

HESSE, Konrad. A força normativa da Constituição. Tradução de Gilmar Ferreira Mendes. Porto Alegre: Sergio Antonio Fabris Editor, 1991.

KELSEN, Hans. Teoria Geral do Direito e do Estado. Tradução: Luís Carlos Borges. 4ª edição. São Paulo: Martins Fontes, 2.005.

KRAUZE, Enrique. El fin del redentorismo iluminado. Disponível em: <http://www.eltiempo.com/archivo/documento/CMS-12671436>. Acesso em: 10 de agosto de 2019.

MÁRQUEZ, Gabriel García. Gabo e a solidão da América Latina. Disponível em: < http://operamundi.uol.com.br/dialogosdosul/gabo-e-a-solidao-da-america-latina/22042014/>. Acesso em: 28.07.2019. 
MENDIBLE Z., Alejandro. Venezuela: su tránsito elíptico en el destino histórico sudamericano y el rol moderador del Brasil en el presente. In: CARMO, Corival Alves do (et. al.) Relações internacionais: olhares cruzados. Brasília: FUNAG, 2013.

NEGRO, Sandra C. Caracterización y classificación de los esquemas de integración. In: NEGRO, Sandra (Directora). Derecho de la Integración. Manual. Buenos Aires: Julio César Faira (Editor), 2010.

PASQUINO, Gianfranco. In: BOBBIO, Norberto; MATTEUCCI, Nicola; PASQUINO, Gianfranco (orgs.). Dicionário de Política. Volume I. Tradução: João Ferreira et. all. Brasília: Editora da Universidade de Brasília, 1998.

RICUPERO, Rubens. A diplomacia na construção do Brasil: 1750-2016. $1^{\text {a }}$ - edição. Rio de Janeiro: Versal Editores, 2017.

ROBLES, Gregorio. Los derechos fundamentales y la ética em la sociedad actual. Reimpresión Revisada. Madrid: Editorial Civitas, S.A., 1997.

RUIZ-VÁSQUEZ, Juan Carlos. Venezuela: el Estado incómodo para la seguridad internacional. ACOSTA VARÓN, Laura Sofía (org.). La crisis venezolana: impactos y desafios. Edición Eduardo Pastrana Buelvas, Hubert Gehring. -- Bogotá : Fundación Konrad Adenauer, 2019.

SEN, Amartya. A ideia de justiça. Tradução: Denise Bottmann e Ricardo Doninelli Mendes. São Paulo: Companhia das Letras, 2.011.

SEN, Amartya. Desenvolvimento como liberdade. Tradução: Laura Teixeira Mota. São Paulo: Companhia das Letras, 2010.

SORJ, Bernardo; MARTUCCELLI, Danilo. O desafio latino-americano: coesão social e democracia. Tradução: Renata Telles. Rio de Janeiro: Civilização Brasileira, 2008.

WILliamsON, Edwin. História da América Latina. Tradução: Patrícia Xavier. Lisboa: Edições 70, 2009. 